\title{
DESENVOLVIMENTO VEGETATIVO E MORFOLOGIA RADICULAR DE CITRANGE CARRIZO AFETADO POR ÁCIDO INDOLBUTÍRICO E MICORRIZAS ARBUSCULARES ${ }^{1}$
}

\author{
VEGETATIVE DEVELOPMENT AND ROOT MORPHOLOGY OF \\ CARRIZO CITRANGE AFFECTED BY INDOLEBUTYRIC \\ ACID AND ARBUSCULAR MYCORRHIZAL FUNGI
}

\author{
Paulo Vitor Dutra de Souza ${ }^{2}$ Manuel Agusti ${ }^{3}$ \\ Manuel Abad ${ }^{3}$ Vicente Almela ${ }^{3}$
}

RESUMO

\begin{abstract}
Este estudo foi realizado na localidade de Alcanar (Tarragona, Espanha) e objetivou avaliar o efeito de cinco concentrações do ácido indolbutírico $(A I B)(0,0 ; 0,5 ; 1,0 ; 1,5 ; 2,0$ $\mathrm{g} / \mathrm{L}$ ) e da inoculação com micorrizas arbusculares (MA) (Glomus intraradices Schenck \& Smith) sobre o desenvolvimento vegetativo, conteúdo foliar de $P$ e K e morfologia radicular de plântulas de citrange Carrizo (Citrus sinensis (L.) X Poncirus trifoliata (L.) Raf.). Utilizou-se o delineamento experimental de blocos completos casualisados em esquema fatorial, com 4 repetições e 10 plantas por parcela. A aplicação de AIB não alterou o desenvolvimento vegetativo das plântulas cultivadas em ausência de $M A$, apesar de haver incrementado a quantidade de $P$ e $K$ e a espessura dos feixes vasculares. As MA incrementaram o conteúdo de P foliar. Encontrou-se uma interação positiva entre o AIB e as $M A$, pois as plântulas micorrizadas apresentaram um incremento no desenvolvimento vegetativo, nos conteúdos foliares de $P$ e $K$ e na espessura dos feixes vasculares com o aumento das concentrações de AIB.
\end{abstract}

Palavras-chave: doses de auxina, micorrizas arbusculares, nutrição mineral, citros.

\section{SUMMARY}

This study was carried out in Alcanar (Tarragona Spain) to evaluate the effect of five indolebutyric acid (IBA) concentrations $(0.0 ; 0.5 ; 1.0 ; 1.5 ; 2.0 \mathrm{~g} / \mathrm{L})$ and inoculation with arbuscular mycorrhizae fungi (AMF) (Glomus intraradices Schenck \& Smith) on Carrizo citrange (Citrus sinensis (L.) $x$ Poncirus trifoliata (L.) Raf.) vegetative development, $P$ and $K$ foliar contents and root morphology. The experimental design was in a Completly Randomized Block Design with 10 seedlings per plot and 4 replicates. The IBA concentrations had no effect on vegetative development of nonmycorrhizal seedlings, althougt it had increased $P$ and $K$ foliar contents and primary xylem tickness. AMF increased $P$ foliar content. IBA x AMF interaction was observed, increasing IBA concentrations on mycorrhizal seedlings resulted in increased in vegetative development, $P$ and $K$ foliar contents and primary xylem thickness.

Key words: auxins, mycorrhizal fungi, mineral nutrition, citrus.

\section{INTRODUÇÃO}

Espécies com uma escassa quantidade de pêlos radiculares, como o caso dos citros (GRAHAM $\boldsymbol{e t} \boldsymbol{a l} .$, 1991) são, em geral, altamente dependentes das micorrizas arbusculares (MA) (POPE $\boldsymbol{e t}$ al., 1983). Estas desempenham um importante papel sobre o transporte de nutrientes de lenta difusão desde o solo até as células da raiz (TOBAR $\boldsymbol{e t}$ al., 1994), além de induzirem uma maior resistência ao estresse hídrico (READ, 1992), culminando com um maior crescimento vegetativo e uma maior resistência ao transplante (DUTRA et al., 1995).

O ácido indolbutírico (AIB) desempenha um papel fundamental no processo de iniciação

\footnotetext{
${ }^{1}$ Extraído do trabalho apresentado para obtenção do título de Doutor em Agronomia pela Universidad Politécnica de Valencia (Espanha). ${ }^{2}$ Engenheiro Agrônomo, Doutor, Departamento de Horticultura e Silvicultura, Faculdade de Agronomia, Universidade Federal do Rio Grande do Sul, CP 776, 91501-970, Porto Alegre, RS, Bolsista CNPq. Autor para correspondência.

${ }^{3}$ Engenheiro Agrônomo, Doutor, Departamento de Producción Vegetal, ETSIA, Universidad Politécnica de Valencia, 46020, Valencia, Espanha.
} 
radicular (MORALES, 1990). No entanto, na fase de elongação radicular, as plantas normalmente não respondem à aplicação de auxinas (HARTMANN $\boldsymbol{e t}$ al., 1989).

Existe um intercâmbio hormonal entre as MA e as plantas hospedeiras (MEYER, 1974), mas a maioria dos estudos realizados para elucidar essas interações foram efetuados com fungos ectomicorrízicos, os quais produzem auxinas, giberelinas, etileno e vitaminas em cultivos puros (MILLER, 1971; CRAFT \& MILLER, 1974; SLANKIS, 1974; BARROSO et al., 1986). Entretanto, a síntese de tais hormônios pelas MA tem sido pouco estudada pela dificuldade de multiplicar-se o fungo em meios de cultura artificiais (COOPER, 1984). Apesar disso, demonstrou-se que Glomus mosseae é capaz de produzir substâncias com ação hormonal (BAREA \& AZCÓN-AGUILAR, 1982).

Há pouca informação sobre modificações anatômicas e histoquímicas produzidas por infecções micorrízicas nos tecidos vegetais (KRISHNA et al., 1981). Há relatos de que as MA não provocam grandes transformações morfológicas nas raízes (COOPER, 1984), apesar de que publicações mais recentes descrevem um incremento na divisão celular e um efeito variável sobre o crescimento das células (ATKINSON et al., 1994).

Este trabalho teve por objetivo avaliar o efeito das micorrizas arbusculares (MA) sobre o desenvolvimento vegetativo, conteúdo foliar de $\mathrm{P}$ e $\mathrm{K}$ e morfologia radicular de plântulas de citrange Carrizo (Citrus sinensis (L.) X Poncirus trifoliata (L.) Raf.), além de verificar se o ácido indolbutírico, aplicado numa fase inativa da planta a auxinas (fase de elongação celular), favorece a atividade das MA e, portanto, a simbiose planta-MA.

\section{MATERIAL E MÉTODOS}

Este estudo foi realizado em casa de vegetação com cobertura plástica (média das temperaturas máximas: $27,4^{\circ} \mathrm{C}$; média das temperaturas mínimas: $13,2^{\circ} \mathrm{C}$; média da umidade relativa máxima: $97,3 \%$; média da umidade relativa mínima: 46,7\%), na localidade de Alcanar (Tarragona - Espanha), utilizando-se como planta teste o citrange Carrizo (Citrus sinensis (L.) Osb. $\mathrm{x}$ Poncirus trifoliata (L.) Raf.).

A semeadura foi realizada em maio de 1994, em bandejas de polietileno contendo uma mistura de areia, perlita e turfa Sphagnum (3:2:1, $\mathrm{v}: \mathrm{v}: \mathrm{v})$. Este meio de cultivo foi desinfetado com Vapam ${ }^{\circledR}$ (Metilditiocarbamato de sódio, $400 \mathrm{ml} / \mathrm{m}^{3}$ de substrato). Utilizou-se um adubo de liberação lenta (Osmocote Plus ${ }^{\circledR} ; 2,5 \mathrm{~kg} / \mathrm{m}^{3}$ de substrato) de 3-4 meses de ação.
Metade das plântulas foram inoculadas com Glomus intraradices (Schenck \& Smith), usando $10 \mathrm{~g} /$ plântula de uma mistura de solo rizosférico e raízes de alfafa cv. Aragón (Medicago sativa L.) contendo propágulos do fungo. O inóculo foi distribuído numa camada colocada a $3 \mathrm{~cm}$ de profundidade no substrato, imediatamente abaixo das sementes. Empregou-se uma mistura esterilizada de raízes e solo rizosférico de alfafa nas plântulas não micorrizadas.

Em setembro, as plântulas foram transferidas para sacos de polietileno preto perfurados, com capacidade para 5 litros. Nesse momento, foram ensaiadas cinco concentrações de ácido indolbutírico (AIB): 0,$0 ; 0,5 ; 1,0 ; 1,5 ; 2,0 \mathrm{~g} / \mathrm{L} .$, aplicadas via radicular, mediante imersão por 10 segundos nas referidas soluções. As plântulas não tratadas com AIB foram tratadas com água destilada.

Usou-se a mesma mistura de substrato empregada na sementeira. A irrigação foi realizada mediante gotejamento a cada 48 horas $\left(665 \mathrm{~cm}^{3} /\right.$ planta). Aplicou-se semanalmente, mediante fertirrigação, por planta, $0,33 \mathrm{~g}$ de nitrato de cálcio; $0,15 \mathrm{~g}$ de nitrato de potássio e $0,04 \mathrm{~g}$ de fosfato monoamônico.

O delineamento experimental foi $\mathrm{o}$ de blocos ao acaso, com 10 plantas por tratamento e repetição, e quatro repetições, totalizando 400 plântulas no experimento.

Onze meses após a semeadura, as plântulas foram colhidas para a realização das determinações previstas. $\mathrm{O}$ diâmetro do colo foi medido na superfície do substrato. A área foliar foi medida mediante o emprego do aparelho LI-COR LI-3000A Area Meter. O peso seco da parte aérea e das raízes foi medido após secagem do material vegetal em estufa a $65^{\circ} \mathrm{C}$, até peso constante.

As raízes das plântulas inoculadas com MA foram examinadas para determinar seu nível de infecção. Em cada tratamento e repetição, coletaram-se duas raízes secundárias por planta, de 10 plantas. As raízes foram lavadas com água e cortadas em fragmentos de $1 \mathrm{~cm}$ de comprimento. Noventa fragmentos por tratamento foram misturados, clarificados e tingidos para determinação da infecção micorrízica, segundo a técnica descrita por PHILLIPS \& HAYMAN (1970). Elas foram montadas em lâminas de vidro e examinadas em microscópio óptico para determinarem a presença e a intensidade de hifas, vesículas e arbúsculos, segundo o método descrito por NEMEC (1992b). A porcentagem de infecção radicular foi calculada pelo número de raízes infectadas, em relação ao total de raízes analisadas. Para determinar a densidade de hifas, atribuiu-se o valor 0 para ausência de estruturas; 1, 
para presença fraca; 2, para presença moderada; e 3, para presença intensa. A densidade de vesículas e arbúsculos também foi relacionada com uma escala de 0 a 3 , onde se considerou como 0 a ausência de estruturas; 1 , para 1 a 50 estruturas; 2, para 51 a 100 ; e 3, para mais de 100 .

Determinou-se o conteúdo foliar de $\mathrm{P}$ e $\mathrm{K}$ nas plântulas testemunha e nas tratadas com $1,0 \mathrm{~g} / \mathrm{L} \mathrm{e}$ 2,0g/L de AIB. Para tanto, as folhas foram lavadas de acordo com LABANAUSKAS (1966). O P foi determinado pelo método do "Molibdenium Blue Colour' (FISKE \& SUBBAROW, 1925) e o K, por fotometria de chama (CHAPMAN \& PRATT, 1961).

Os estudos histológicos foram realizados somente nas plântulas inoculadas e não inoculadas com MA, tratadas com $0,0 \mathrm{~g} / \mathrm{L}$ e $1,0 \mathrm{~g} / \mathrm{L}$ de $\mathrm{AIB}$, pois foi onde se encontraram plântulas com desenvolvimento vegetativo semelhante entre si (altura e diâmetro do colo). Nestas, escolheram-se raízes secundárias com diâmetro também semelhante. Para cada tratamento, utilizaram-se cinco raízes secundárias de cinco plântulas, fazendo-se no mínimo, 5 cortes transversais por raiz, após sua inclusão em parafina. Todo o processo de preparação das raízes, como fixação, desidratação, infiltração, inclusão, corte, montagem e tingimento, foram realizados segundo adaptações ao método descrito por JOHANSEN (1940). Em cada corte, realizaram-se 3 medições da espessura do córtex e do número linear de suas células, obtendo-se por divisão destes valores, o diâmetro das células. O mesmo processo foi empregado para a determinação das características do xilema primário e da medula.

Os resultados foram submetidos à análise de variância e ao teste de comparação de médias, DMS a $5 \%$ de probabilidade, ou por meio de análise de regressão.

\section{RESULTADOS E DISCUSSÃO}

O diâmetro do colo das plântulas de citrange Carrizo foi positivamente afetado pelas MA, encontrando-se uma interação significativa entre este fator e as doses de AIB aplicadas (Figura 1). À semelhança do ocorrido para a altura das plântulas (dados não apresentados), as doses de AIB se mostraram ineficazes em plântulas não micorrizadas, mas, em presença de MA, o diâmetro do colo incrementou linearmente com o aumento das concentrações da auxina, possibilitando antecipar a enxertia e, dessa forma, reduzir o período de produção de mudas.

$\mathrm{O}$ peso seco da parte aérea (Figura $2 \mathrm{~A}$ ) e das raízes (Figura 2B) também foi positivamente afetado pelas MA, ocorrendo uma interação signifi-

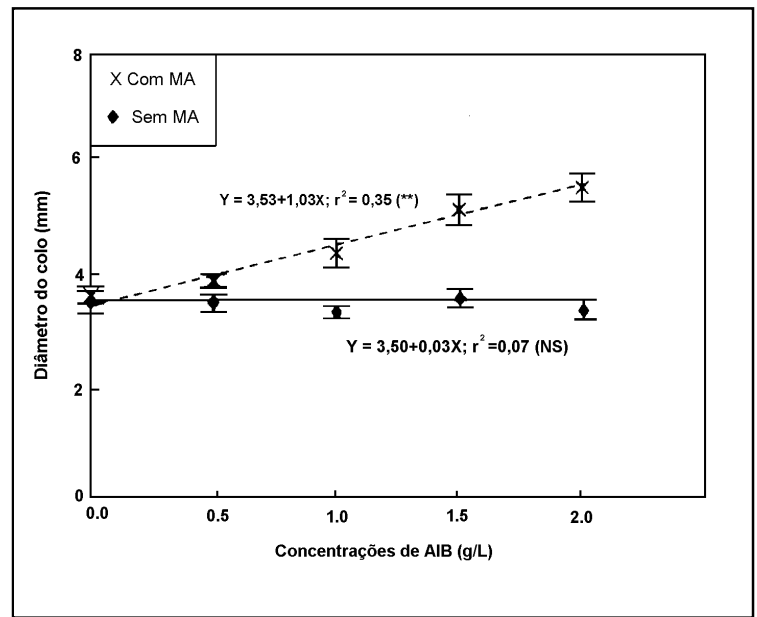

Figura 1 - Diâmetro do colo de plântulas de citrange Carrizo de onze meses de idade, com a aplicação de ácido indolbutírico (AIB) na presença e ausência de micorrizas arbusculares (MA).

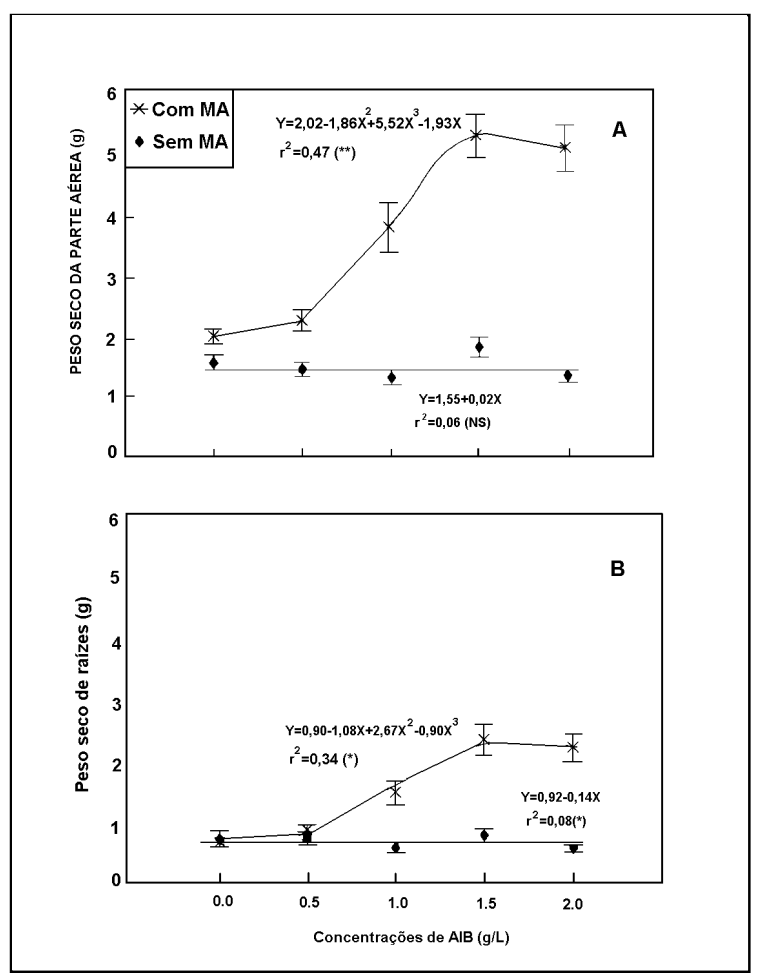

Figura 2 - Peso seco da parte aérea (a) e das raízes (b) de plântulas de citrange Carrizo de onze meses de idade, com a aplicação de ácido indobutírico (AIB) na presença e ausência de micorrixas arbusculares (MA). 
cativa entre esse fator e as doses de AIB aplicadas. As doses de AIB não alteraram o peso seco da parte aérea e das raízes das plantas não micorrizadas. Nas plantas micorrizadas, no entanto, proporcionaram um incremento no peso seco dessas plantas a partir de $1,0 \mathrm{~g} / \mathrm{L}$ de $\mathrm{AIB}$, resposta que se saturou na dose de $1,5 \mathrm{~g} / \mathrm{L}$.

As plântulas micorrizadas apresentaram um maior número de folhas, como conseqüência da maior altura das plântulas (Figura 3A). A interação AIB x MA também foi significativa para esse fator. O número de folhas não variou nas plântulas cultivadas em ausência de MA, mas, em presença do fungo, ampliou com o aumento das concentrações de AIB, passando de 25 folhas por plântula nas testemunhas a, aproximadamente, 45 nas concentrações mais elevadas.

A superfície média das folhas também foi afetada pelos tratamentos (Figura 3B). Ela não foi alterada nas plântulas não micorrizadas, situando-se ao redor dos $5,8 \mathrm{~cm}^{2}$. Já nas plântulas micorrizadas, a área foliar aumentou a partir dos $0,5 \mathrm{~g} / \mathrm{L}$ de AIB, saturando-se na concentração de $1,5 \mathrm{~g} / \mathrm{L}$. Também para este parâmetro de avaliação, a interação AIB x MA foi significativa.

Os resultados até aqui encontrados evidenciam o efeito positivo das MA sobre o desenvolvimento vegetativo dos citros, confirmando os resultados de Nemec (1992a) e DUTRA et al. (1995).

Um aspecto interessante, que permite avançar no conhecimento da atividade das MA, consiste na ação das auxinas de síntese e sua interação com esse tipo de fungo sobre o desenvolvimento vegetativo das plântulas cítricas. $\mathrm{O}$ efeito do AIB parece ser independente do das MA. Enquanto estas incrementam a eficiência na absorção nutricional (BAREA, 1991), o AIB desempenha um papel fundamental no processo de iniciação radicular (MORALES, 1990). Estes efeitos somados poderiam ser responsáveis pelo incremento no desenvolvimento vegetativo. Entretanto, como o AIB é ineficaz em ausência de MA, está claro que há um efeito interativo entre ambos. De acordo com HARTMANN $\boldsymbol{e t}$ al. (1989), as plantas não respondem à aplicação de auxinas durante a fase de elongação radicular. Isso justificaria a ausência de resposta encontrada com o AIB aplicado às plântulas não micorrizadas. A resposta encontrada com o AIB em plântulas micorrizadas consolida a interação existente entre estas variáveis, demonstrando serem esses fungos intermediários no aproveitamento do AIB, aplicado nesta fase vegetativa. A promoção do crescimento por parte do AIB em presença de MA também foi detectada com a ectomicorriza Pisolithus tinctorius (GREENE et al., 1982).

Em geral, o número de estruturas de MA se manteve aproximadamente constante até a con-

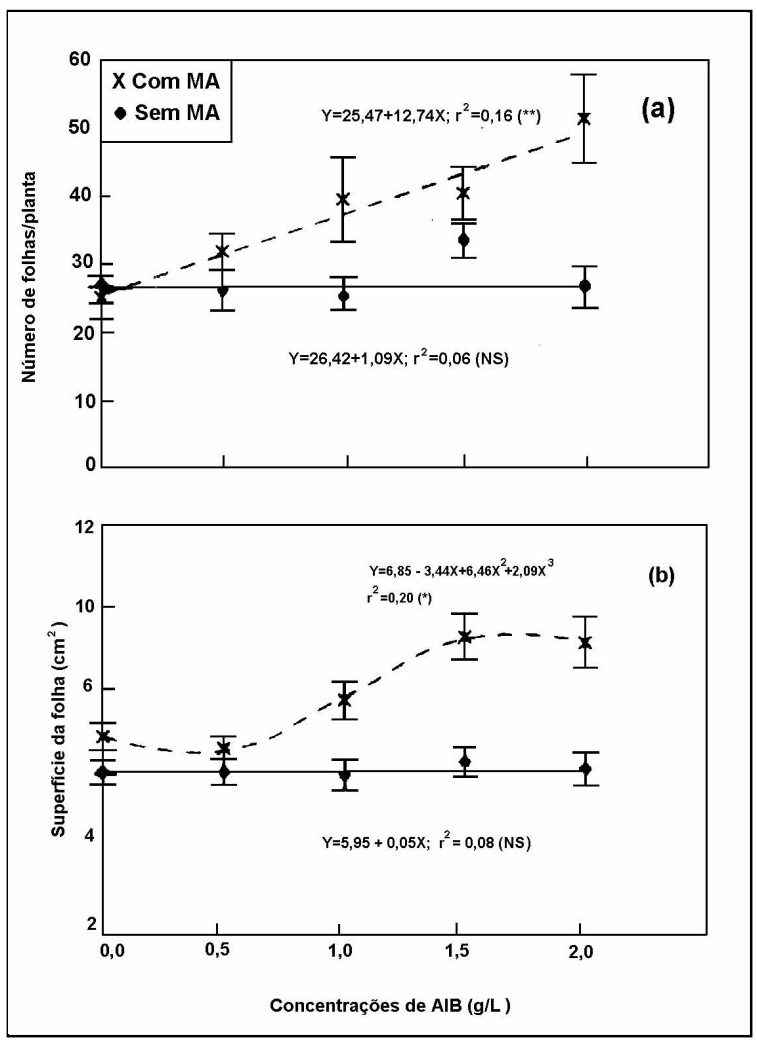

Figura 3 - Número e superfície das folhas de plântulas de citrange Carrizo de onze meses de idade, com a aplicação de ácido indolbutírico (AIB) na presença e ausência de micorrizas arbusculares (MA)

centração de 1,0g/L de AIB (Figura 4). A partir desta, houve um importante incremento na densidade de estruturas do endófito, que alcançou seu máximo na concentração de $1,5 \mathrm{~g} / \mathrm{L}$. O aumento na concentração de $\mathrm{AIB}$ até $2,0 \mathrm{~g} / \mathrm{L}$ não alterou o número de hifas e provocou um decréscimo no número de vesículas e arbúsculos. Este comportamento indica que a auxina afeta diretamente a colonização por parte das MA, sendo, inclusive, prejudicial em doses excessivas.

A micorrização das plântulas e a aplicação de AIB afetaram significativamente o conteúdo foliar de P (Figura 5a) e K (Figura 5b). A interação AIB x MA foi significativa para o conteúdo foliar de $\mathrm{P}$, não o sendo para o $\mathrm{K}$. Com o aumento da concentração de AIB, houve um incremento linear nos conteúdos foliares de $\mathrm{P}$, que foi mais marcante nas plântulas micorrizadas. No caso do K, também se notou um incremento linear no conteúdo foliar desse nutriente com o aumento da concentração de AIB, independentemente da presença de MA.

As MA têm um efeito direto sobre o desenvolvimento das plantas, absorvendo nutrientes por suas hifas e translocando-os para a planta 


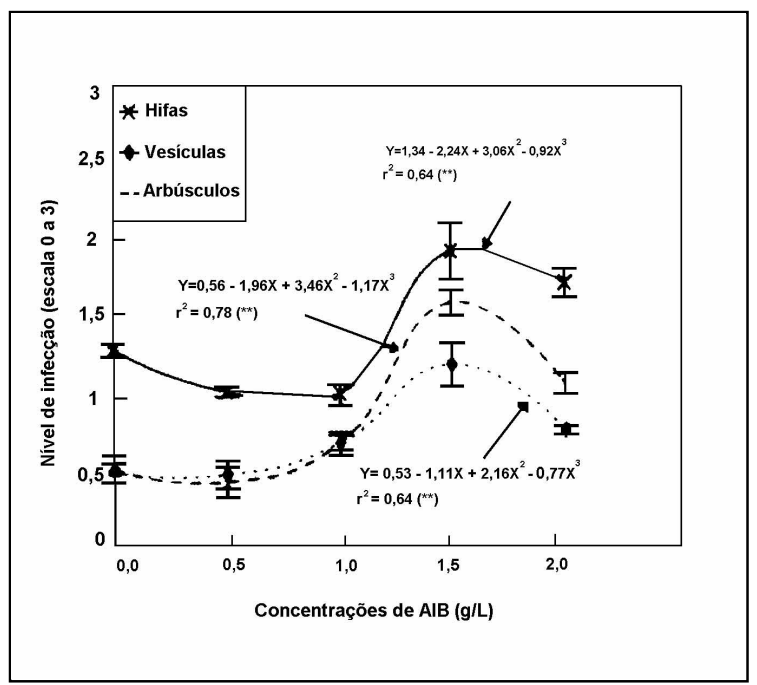

Figura 4 - Densidade de estruturas de micorrizas arbusculares (MA) em raízes de citrange Carrizo de onze meses de idade, com a aplicação de ácido indolbutírico (AIB).

(BAREA, 1991; AN et al., 1993). Dentre os nutrientes mais absorvidos pelas MA se encontra o P (KRISHNA \& BAGYARAJ, 1981; DUTRA et al., 1996), tendo, contudo, a capacidade de absorver outros nutrientes, como o K (AZCÓN-AGUILAR \& BAREA, 1992); comportamento que coincide com os resultados encontrados no presente estudo.

Um aspecto interessante deriva do estudo nutricional das plantas tratadas com AIB em presença de MA. Nesse caso, encontra-se um incremento nos conteúdos de $\mathrm{P}$ e $\mathrm{K}$ com o aumento das concentrações da auxina, que para o $\mathrm{P}$ é mais acentuado em presença de MA. Esse efeito pode ter sido consequiência de um aumento na infecção por ação do AIB (Figura 4), pois, possuindo o micélio externo um papel fundamental no transporte de nutrientes de difusão lenta no solo até as células da raiz, ele viabiliza uma maior eficiência da nutrição (TOBAR et al., 1994).

Como foi anteriomente referido, as raízes escolhidas para os estudos histológicos tinham, estatisticamente, o mesmo diâmetro, apesar de que, nas testemunhas (sem AIB e sem MA), apresentaram um diâmetro que superava em, aproximadamente, $10 \%$ os tratamentos restantes (Tabela 1).

A aplicação de AIB reduziu a espessura do córtex, principalmente pela diminuição do número de suas células (Tabela 1). O efeito das MA sobre a espessura do córtex foi significativo e independente do AIB, verificando-se uma redução na espessura do córtex das plantas micorrizadas, devido à diminuição no tamanho das células.

Esse comportamento coincide com as observações realizadas por ATKINSON et al. (1994),

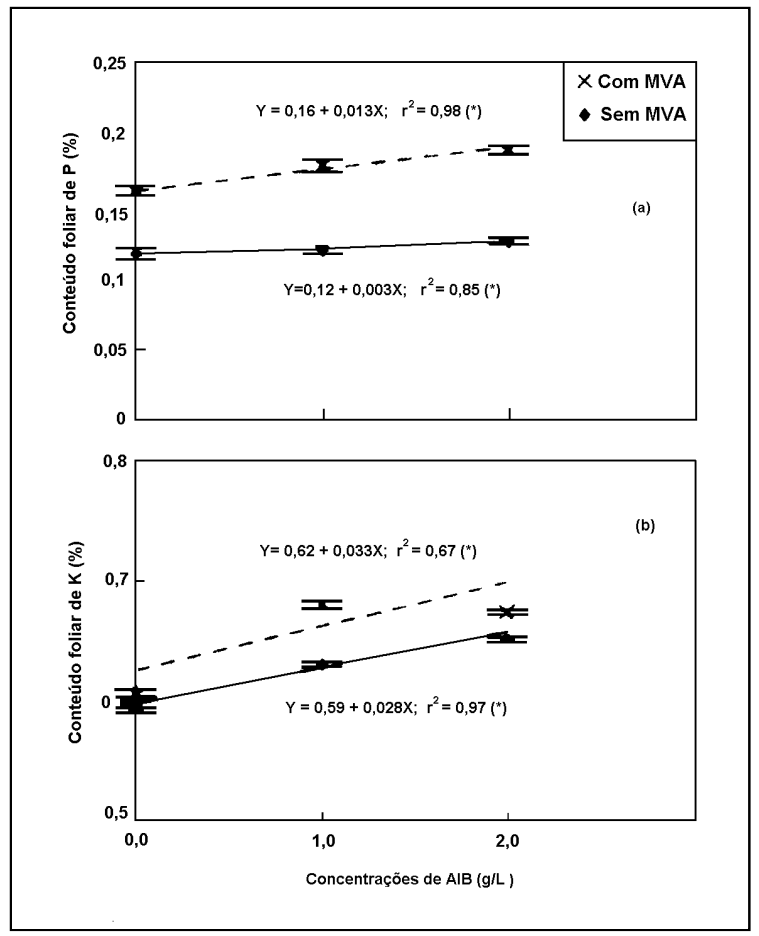

Figura 5 - Conteúdo foliar de P (a) e K (b) em plântulas de citrange Carrizo de onze meses de idade, com a aplicação de ácido indolbutírico (AIB) na presença e ausência de micorrizas arbusculares (MA).

que relatam um efeito variável das MA sobre o crescimento celular. Outros autores não encontram modificações morfológicas provocadas pelas MA a nível radicular (LINDERMAN \& HENDRIX, 1982; COOPER, 1984).

A aplicação de AIB e as MA afetaram significativamente a espessura do xilema primário (Tabela 1). A interação entre esses fatores foi significativa para esse parâmetro. A auxina induziu a uma duplicação na espessura do xilema primário, devido a um incremento no tamanho e número de células. Quando aplicada em plantas micorrizadas, quadruplicou-o pelo mesmo motivo. As MA, em ausência de AIB, não afetaram a espessura do xilema primário, mas em presença da auxina duplicaram-no, devido a um aumento no número de células. Esse incremento, em número e tamanho dos feixes vasculares, também pode ter facilitado, juntamente com o aumento da infecção micorrízica, a absorção nutricional.

A espessura da medula foi significativamente afetada pelas doses de AIB e pelas MA, encontrando-se uma interação altamente significativa entre esses fatores (Tabela 1). As MA incrementaram o raio da medula das plantas não tratadas com AIB, como conseqüência de um aumento no número de células, através da ação do endófito, acentuando a 
Tabela 1 - Morfologia das raízes secundárias de citrange Carrizo com a aplicação de ácido indolbutírico (AIB) na presença e ausência de micorrizas arbusculares (MA)

\begin{tabular}{|c|c|c|c|c|c|c|c|c|c|c|c|}
\hline \multirow[t]{2}{*}{$\begin{array}{l}\text { Doses de } \\
\text { AIB (g/L) }\end{array}$} & \multirow[t]{2}{*}{ Tratamento } & \multirow[t]{2}{*}{$\begin{array}{c}\varnothing \mathrm{da} \\
\operatorname{raiz}(\mu \mathrm{m})\end{array}$} & \multicolumn{3}{|c|}{ Córtex } & \multicolumn{3}{|c|}{ Xilema primário } & \multicolumn{3}{|c|}{ Medula } \\
\hline & & & $\begin{array}{c}\text { Espessu- } \\
\text { ra } \\
(\mu \mathrm{m})\end{array}$ & $\begin{array}{l}\mathrm{N}^{\circ} \mathrm{de} \\
\text { células }\end{array}$ & $\begin{array}{c}\varnothing \text { das } \\
\text { células } \\
\mu \mathrm{m})\end{array}$ & $\begin{array}{c}\text { Espessu- } \\
\text { ra } \\
(\mu \mathrm{m})\end{array}$ & $\begin{array}{l}\mathrm{N}^{\circ} \text { de } \\
\text { células }\end{array}$ & $\begin{array}{l}\varnothing \text { das } \\
\text { células } \\
(\mu \mathrm{m})\end{array}$ & $\begin{array}{c}\text { Espessu- } \\
\text { ra } \\
(\mu \mathrm{m})\end{array}$ & $\begin{array}{l}\mathrm{N}^{\circ} \mathrm{de} \\
\text { células }\end{array}$ & $\begin{array}{c}\varnothing \text { das } \\
\text { células } \\
(\mu \mathrm{m})\end{array}$ \\
\hline \multirow[t]{2}{*}{0,0} & Com MA & 867,35 & $242,14^{1}$ & 13,22 & 18,16 & $29,08 \mathrm{c}$ & $4,95 \mathrm{c}$ & $5,92 \mathrm{c}$ & $173,16 \mathrm{a}$ & $14,41 \mathrm{a}$ & 12,35 \\
\hline & Sem MA & 943,06 & 314,39 & 14,46 & 21,84 & $36,22 \mathrm{c}$ & $4,84 \mathrm{c}$ & $7,45 \mathrm{~b}$ & $136,12 \mathrm{~b}$ & $10,32 \mathrm{~b}$ & 13,37 \\
\hline \multirow[t]{2}{*}{1,0} & Com MA & 891,63 & 206,84 & 11,10 & 19,29 & $135,31 \mathrm{a}$ & $14,70 \mathrm{a}$ & 9,18 a & $112,24 \mathrm{c}$ & $7,47 \mathrm{c}$ & 15,20 \\
\hline & Sem MA & 823,06 & 235,51 & 10,44 & 22,96 & $63,27 \mathrm{~b}$ & $7,53 \mathrm{~b}$ & 8,67 a & $116,22 \mathrm{c}$ & $6,50 \mathrm{c}$ & 17,24 \\
\hline \multirow{3}{*}{\multicolumn{2}{|c|}{$\begin{array}{l}\text { Efeito dose de AIB } \\
\text { Efeito MA } \\
\text { Interação }\end{array}$}} & NS & $* *$ & $* *$ & NS & $* *$ & $* *$ & $* *$ & $* *$ & $* *$ & $* *$ \\
\hline & & NS & $* *$ & NS & $* *$ & $* *$ & $* *$ & NS & $*$ & $* *$ & $*$ \\
\hline & & NS & NS & NS & NS & $* *$ & $* *$ & $* *$ & $* *$ & $*$ & NS \\
\hline
\end{tabular}

${ }^{1}$ Letras diferentes na mesma coluna indicam diferenças significativas.

*,**,NS= significativo a $5 \%, 1 \%$ e não significativo, respectivamente, pelo teste DMS

divisão celular. Este efeito também é relatado por ATKINSON et al. (1994). Em presença de AIB, no entanto, não houve efeito das MA. A aplicação da auxina induziu uma redução na espessura da medula, sendo mais acentuado em presença de MA. Esse comportamento deveu-se a uma diminuição no número de células. Apesar disso, o AIB provocou um aumento e as MA uma diminuição no tamanho das células.

O papel dos fitorreguladores nos processos de micorrização, como já referido, é pouco conhecido e as referências experimentais a respeito são escassas. Contudo, demonstrou-se que as MA provocam alterações nos conteúdos endógenos de fitorreguladores por interações simbióticas e parasíticas (EDRISS et al., 1984; HOCK et al., 1992). Os resultados encontrados neste experimento põem em evidência que os fitorreguladores estão diretamente ligados às interações planta-MA.

\section{CONCLUSÕES}

A aplicação de AIB não é uma prática eficiente para o aumento do desenvolvimento vegetativo de plântulas de citrange Carrizo não micorrizadas.

A aplicação de AIB associada à inoculação de plântulas de citrange Carrizo com MA propicia incremento no desenvolvimento vegetativo, nos níveis de $\mathrm{P}$ e $\mathrm{K}$ foliares e nas dimensões dos feixes vasculares destas, indicando que a auxina favorece a simbiose planta-MA.

\section{AGRADECIMENTOS}

À empresa VIVEROS GURBÍ S.A.T. (AlcanarTarragona-Espanha) pelo financiamento deste estudo, mediante convênio de colaboração com a Universidad Politécnica de Valencia (Espanha) (convênio n 60930028/70).

\section{REFERÊNCIAS BIBLIOGRÁFICAS}

AN, Z.Q., SHEN, T., WANG, H.G. Mycorrhizal fungi in relation to growth and mineral nutrition of apple seedlings. Scientia Horticulturae, Amsterdam, v. 54, p. 275-285, 1993.

ATKINSON, D., BERTA, G., HOOKER, J.E. Impact of mycorrhizal colonization on root architecture, root longevity and the formation of growth regulators. In: GIANINAZZI,S. SCHÜEPP, H. (Eds.). Impact of Arbuscular Mycorrhizas on Sustainable Agriculture and Natural Ecosystems. Birkhäuser: Verlag Basel, 1994. p. 89-99.

AZCÓN-AGUILAR, C., BAREA, J.M. Interactions between mycorrhizal fungi and other rhizosphere microorganisms. In: ALLEN, M.F. (Ed.). Mycorrhizal Functioning: an integractive plant-fungal process. New York: Chapman \& Hall, 1992. p. 163-198.

BAREA, J.M., AZCÓN-AGUILAR, C. Production of plant growthregulating substances by the vesicular-arbuscular mycorrhizal fungus Glomus mosseae. Applied and Environmental Microbiology, Washington, DC, v. 43, p. 810-813, 1982.

BAREA, J.M. Vesicular-arbuscular mycorrhizae as modifiers of soil fertility. In: STEWART, B.S. (Ed.). Advances in Soil Science. New York: Springer-Verlag, 1991, v. 15, 40 p.

BARROSO, J., NEVES, H.C., PAIS, M.S. Production of indole-3-ethanol and indole-3-acetic acid by the mycorrhizal fungus of Ophrys lutea (Orchidaceae). The New Phytologist, Cambridge, v. 103, p. 745-749, 1986.CHAPMAN. M.D., PRATT, P.F. Methods of analysis for soils, plants and waters. Riverside: University of California. Division of Agricultural Science, 1961. p. 150-161. 
CHAPMAN M.D., PRATT, P.F. Methods of analysis for soils, plants and waters. Riverside: University of California. Division of Agricultural Science, 1961. p. 150-161.

COOPER, K.M. Physiology of VA Mycorrhizal Associations. In: POWEL, C.L.; BAGYARAJ, J. (Eds.). VA Mycorrhiza. Boca Raton: CRC, 1984, p. 155-186.

CRAFT, C.B., MILLER, C.O. Detection and quantification of citokinins produced by mycorrhizal fungi. Plant Physiology, Bethesda, v. 54, p. 586-588, 1974.

DUTRA, P.V., ALMELA, V., PONS, J., et al. Inoculación de patrones de cítricos con micorrizas vesiculares-arbusculares y su comportamiento en los suelos de vivero. Phytoma, Valencia, n. 65, p. 17-22, 1995.

DUTRA, P.V., ABAD, M., ALMELA, V., et al. Auxin interaction with the vesicular-arbuscular mycorrhizal fungus Glomus intraradices Schenck \& Smith improves vegetative growth of two citrus rootstocks. Scientia Horticulturae, Amsterdan, v. 66, p. 77-83, 1996.

EDRISS, M.H., DAVIS, R.M., BURGER, D.W. Increased growth responses of citrus by several species of mycorrhizal fungi. HortScience, Alexandria, v. 19, n. 4, p. 537-539, 1984

FISKE, C.H., SUBBAROW, Y. The colorimetric determination of phosphorus. Journal of Biological Chemistry, Bethesda, v. 66 , p. $375-400,1925$.

GRAHAM, J.H., EISSENSTAT, D.M., DROVILLARD, D.L. On the relationship between a plant's mycorrhizal dependency and rate of vesicular-arbuscular mycorrhizal colonization. Functional Ecology, Oxford, v. 5, p. 773-779, 1991.

GREENE, D.W., MANNING, W.J., COOLEY, D.R. Effect of the ectomycorrhizal fungus Pisolithus tinctorius and auxin rooting formulations on growth of 'Cortland' apple trees. HortScience, Alexandria, v. 17, n. 4, p. 655-656, 1982.

HARTMANN, H.T., KESTER, D.E., DAVIES, F.T. Plants propagation: principles and practices. 5. ed. Englewood Cliffs: Prentice-Hall, 1989. p. 199-255.

HOCK, B., LIEBMANN, S., BEYRLE, H., et al. Phytohormone analysis by enzyme immunoassays. Methods in Microbiology, v. 24, p. 249-273, 1992.

JOHANSEN, D.A. Plant microtechnique. New York: McGrawHill, 1940. 523 p.

KRISHNA, K.R., BAGYARAJ, D.J. Note on the effect of VA mycorrhiza and soluble phosphate fertilizer on sorghum. The Indian Journal of Agricultural Sciences, Nova Deli, v. 51, p. 688-690, 1981.
KRISHNA, K.R., SURESH, H.M., SYAMSUNDER, J., et al. Changes in the leaves of finger millet due to VA Mycorrhizal infection. New Phytologist, Cambridge, v. 87, p. 717-722, 1981.

LABANAUSKAS, D.K. Effects of orange leaf-washing techniques on removal of surface contaminants and nutrients losses. Journal of the American Society for Horticultural Science, Alexandria, v. 89 , p. 201-205, 1966 .

LINDERMAN, R.G., HENDRIX, J.W. Evaluation of plant response to colonization by vesicular-arbuscular mycorrhizal fungi. In: SCHENCK, N.C. (Ed.). Methods and principles of mycorrhizal research. St. Paul: Univ. of Florida, 1982, p. 69-70.

MEYER, F.H. Physiology of mycorrhizae. Annual Review of Plant Physiology, Palo Alto, v. 25, p. 567-586, 1974.

MILLER, C.O. Cytokinin production by mycorrhizal fungi. In: HACSKAYLO, E. (Ed.). Mycorrhizae. Washington: United States Government Printing Office, 1971. p. 168-174.

MORALES, C.F.G. Influência do ácido indolbutírico e da presença de folhas no enraizamento de estacas de laranjeiras "Valência" e tangerineiras "Montenegrina". Porto Alegre-RS, 1990. 71 p. Dissertação (Mestrado em Fitotecnia) - Programa de Pós-graduação em Agronomia, Universidade Federal do Rio grande do Sul. 1990.

NEMEC, S. Glomus intraradix effects on citrus rootstocks seedling growth in various potting media. Journal of Agricultural Science, Cambridge, UK, v. 118, p. 315-323, 1992a.

NEMEC, S. Plant roots as mycorrhizal fungus inoculum for citrus grown in the field in Florida. Advances in Horticultural Sciences, Firenze, v. 6, p. 93-96, 1992b.

PHILLIPS, J.M., HAYMAN, D.S. Improved procedures for cleaning roots and staining parasitic and vesicular-arbuscular mycorrhizal fungi for rapid assessment of infection. Transactions of the British Mycological Society, Londres, v. 55, p. 158-161, 1970.

POPE, P.E., CHANEY, W.R., RHODER, J.D., et al. The mycorrhizal dependency of four hardwood tree species. Canadian Journal of Botany, Ottawa, v. 61, p. 412-417, 1983.

READ, D.J. The mycorrhizal mycelium. In: ALLEN, M.F. (Ed.). Mycorrhizal Functioning: an integractive plant-fungal process. New York: Chapman \& Hall, 1992. p. 102-133.

SLANKIS, V. Soil factors influencing formation of mycorrhizae Annual Review of Phytopathology, Palo Alto, v. 12, p. 437457, 1974

TOBAR, R., AZCÓN, R., BAREA, J.M. Improved nitrogen uptake and transport from ${ }^{15} \mathrm{~N}$-labelled nitrate by external hyphae of arbuscular mycorrhiza under water-stressed condictions. New Phytologist, Cambridge, UK, v. 126, p. 119-122, 1994.

Ciência Rural, v. 30, n. 2, 2000. 